Check for updates

Oxford Uehiro Centre for Practical Ethics, Faculty of Philosophy, University of Oxford, UK

2 John Radcliffe Hospital, Oxford, UK

3 Murdoch Children's Research Institute, Melbourne, Australia

4 Cardiff University, UK

5 Oxford Vaccine Group, Department of Paediatrics, University of Oxford, UK

6 NIHR Oxford Biomedical Research Centre, Oxford, UK

7 Faculty of Law, University of Oxford, UK

8 Department of Philosophy, University of Western Ontario, Canada

Correspondence to: D Wilkinson dominic.wilkinson@philosophy.ox.ac.uk A Skelton askelto4@uwo.ca

Cite this as: BMJ2021;374:n1687 http://dx.doi.org/10.1136/bmj.n1687 Published: 09 July 2021

\title{
COVID-19
}

\section{Should we delay covid-19 vaccination in children?}

The net benefit of vaccinating children is unclear, and vulnerable people worldwide should be prioritised instead, say Dominic Wilkinson, Ilora Finlay, and Andrew J Pollard. But Lisa Forsberg and Anthony Skelton argue that covid-19 vaccines have been approved for some children and that children should not be disadvantaged because of policy choices that impede global vaccination Dominic Wilkinson, ${ }^{1,2,3}$ llora Finlay, ${ }^{4}$ Andrew J Pollard, ${ }^{2,5,6}$ Lisa Forsberg, ${ }^{1,7}$ Anthony Skelton ${ }^{8}$

\section{Yes-Dominic Wilkinson, Ilora Finlay, and Andrew J Pollard}

For a health system to offer any vaccine to a child, two key ethical questions must be asked. First, do the benefits outweigh the risks? Second, if the vaccine is in short supply, does someone else need it more? Careful attention to both questions suggests that we should not yet roll out covid-19 vaccination to otherwise healthy children.

Covid-19 vaccines in adults have been remarkably effective. There is good reason to expect that the same will be true in children. Preliminary studies in adolescents indicate high levels of antibody production and 93-100\% effectiveness in preventing covid-19. ${ }^{12}$ This has led to licensing decisions in the UK, the US, and elsewhere.

\section{Less benefit}

In older adults, the benefits of covid vaccines clearly outweigh the rare side effects. But in children there are some key differences.

First, we know less about the risks. Randomised trials to date have given vaccines to only about 3500 adolescents. These trials are not designed to identify rare side effects. ${ }^{3}$ For example, the US government's Centers for Disease Control and Prevention has recently identified a risk of myocarditis in adolescents who have received mRNA based covid-19 vaccines (an estimated 56-69 cases per million vaccine doses). ${ }^{4}$ We do not know whether other complications will emerge.

Second, the potential benefit in children is much smaller. Most children who get covid-19 have mild illness. There are low risks of hospital admission and death (around two per million children in the UK), as well as rare multisystem inflammatory syndrome. ${ }^{56}$ There are also indirect effects (for example, interrupted education) and potential long covid. However, serious illness from covid is much less common than in adults. Moreover, young children and schools seem to play a limited role in transmission. ${ }^{7}$ Vaccination of children would have marginal benefit in protecting others, particularly once people at higher risk are immunised. ${ }^{8}$

Before we roll out a covid-19 vaccine for children, we should scrutinise safety data carefully and wait if there is any uncertainty. Crucially, if reports of serious complications arise they could harm our wider immunisation programme. Community confidence in vaccination can be easily threatened, ${ }^{3}$ leading to surges in vaccine preventable disease. ${ }^{9}$

The difficult question is, do the benefits outweigh the risks? In children with certain chronic or acute serious illnesses they probably do, and these children should therefore have access to a vaccine. But in otherwise healthy children, no one can currently be sure.

\section{Global inequity}

We can be sure of one thing, however. In the UK, some people are currently at much higher risk from covid-19 than healthy children. And most lower income countries have fully vaccinated less than $5 \%$ of their community. ${ }^{10}$ Nepal, which is facing a severe surge of the delta variant, suspended its vaccination programme last month because of a lack of vaccine supply and infrastructure. ${ }^{11}$

Some experts have argued that the number of doses required to vaccinate children in high income countries is small, but in many countries the entire at-risk older population could be vaccinated if they received a number of doses equivalent to the number of UK schoolchildren.

The UK has committed funds to Covax, a worldwide initiative aimed at equitable access to covid-19 vaccines directed by Gavi, the Vaccine Alliance, as well as the Coalition for Epidemic Preparedness Innovations and the World Health Organization. It has promised to donate 100 million surplus doses over the next year, but most doses promised by wealthy countries will not arrive until the end of 2021 or next year. In the meantime, further variants are emerging.

Some might ask, why do we have to choose? Can't we vaccinate children as well as people overseas? But, to put it simply, there are right now a limited number of vaccine doses. As adults, we have had to wait our turn for the vaccine. We have understood that, given its scarcity, the vaccine has to be prioritised for people at the highest risk of dying. This clear and inescapable ethic now applies to our children. Their turn will come-but not yet.

\section{No-Lisa Forsberg and Anthony Skelton}

The UK government is deciding whether to extend its vaccination programme to children aged 12 and older, after the Medicines and Healthcare Products 
Regulatory Agency approved the Pfizer-BioNTech vaccine for this age group. ${ }^{12}$

We have recently argued in the Conversation, an independent academic news source, that there are three broad reasons to vaccinate children against covid-19 ${ }^{13}$ : it protects children themselves from the risk of harm and death from infection; it protects others; and it is the best way to promote children's wellbeing by minimising the need for restrictions or disruptions to their lives resulting from failure to properly manage infection spread. Here we respond to two further arguments for delaying vaccination in children.

\section{Safe and effective}

One argument, despite the existence of safe and effective vaccines, is that the cost-benefit ratio of covid-19 vaccination is less advantageous for children than for older people. Children are less likely to be severely harmed by covid-19 infection, and they therefore benefit less from a vaccination protecting them from it. Further, the argument continues, because we have limited knowledge of the long term effects of covid-19 vaccination in children, we should delay vaccinating them.

But this argument is mistaken. Medical authorities have judged covid-19 vaccines to be safe and effective for children, and they have so far been approved for use in children aged 12 and over. The European Medicines Agency states that any risks in this age group are outweighed by the benefits, ${ }^{14}$ and Health Canada and the US Centers for Disease Control and Prevention agree.

Millions of children have been vaccinated. Side effects so far are extremely rare. And, while the immediate severe effects of covid-19 are considerably less common in children than in older adults, a child has a considerably greater risk of harm from covid-19 infection than from vaccination against it. Children can be severely affected by covid-19 infection: they may die as a result, or they may develop long covid or multisystem inflammatory syndrome. ${ }^{15}$

It is true that we have limited knowledge of the long term effects of covid-19 vaccination. But vaccines in use are closely monitored, enabling us to act on any unexpected side effects, as we did with the AstraZeneca vaccine.

It is also equally true that we have limited knowledge of the long term effects of covid-19 infection. And in the case of infection, there has been limited (if any) monitoring of mild and asymptomatic cases, as these have been thought to be largely unproblematic. But we now know that people with mild or asymptomatic infection may nevertheless develop long term health complications. ${ }^{16}$

Delaying vaccination against covid-19 in children is not, then, the more risk averse decision. Doing so exposes children to unknown risks of severe disease and of long term health complications. And, of course, new variants can occur from permitting extensive infection spread in young people in rich countries, too.

Moreover, we now know that exposing children to those risks disproportionately harms already disadvantaged children. The effects of delaying vaccination are seen in the recent outbreak in the Kashechewan First Nation in northern Ontario. Despite most adults in this population already being vaccinated, of the roughly 300 people infected with covid-19 most were aged under $18 .{ }^{17}{ }^{18}$ Those who are already disadvantaged are thus exposed to known and unknown risks of harm.

\section{Pharma profits}

A second argument for delaying the vaccination of children is that priority should be given to older adults in developing countries where vaccine supply has been limited. A key assumption of this argument is mistaken.

Global vaccine supply is currently limited, and some countries have severe shortages. The shortages result from a policy choice.

Governments in rich countries have-even in an

emergency-prioritised drug companies' interests in making a profit over health and life, despite many governments having invested considerably in vaccine development at risk and despite much of the scientific endeavour occurring in publicly funded universities, such as Oxford.

The ethically defensible choice is to exert whatever pressure we can to minimise vaccine hoarding and distribute vaccines to developing countries, while releasing patents and allowing the manufacture and supply of vaccines on a larger scale, to enable vaccination of adults and children everywhere. ${ }^{19-22}$

Accepting the "austerity" narrative that children must wait until the most vulnerable people in other countries can be vaccinated diverts focus from the real problem: that profits are valued over lives. We should be calling for change, not accepting manufactured scarcity as inevitable.

This research was funded in whole, or in part, by the Wellcome Trust [203132/Z/16/Z] and by the Arts and Humanities Research Council as part of the UK Research and Innovation rapid response to covid-19 [AH/N013947/1]. The funders had no role in the preparation of this manuscript or the decision to submit for publication. For the purpose of open access the author has applied a CC BY public copyright licence to any author accepted manuscript version arising from this submission.

Competing interests: IF is chair of the National Mental Capacity Forum, member of the Welsh Medical Ethics Advisory Group, and member of the All Party Parliamentary Group on Coronavirus inquiry. AJP is chair of the UK Department of Health and Social Care's (DHSC) Joint Committee on Vaccination \& Immunisation (JCVI) but does not participate in policy decisions on covid-19 vaccine; he is also a member of the World Health Organization's Strategic Advisory Group of Experts on Immunisation. The views expressed in this article do not necessarily represent the views of DHSC, JCVI, or WHO. AIP is chief investigator on clinical trials of Oxford University's covid-19 vaccine funded by the National Institute for Health Research. Oxford University has entered a joint covid-19 vaccine development partnership with AstraZeneca.

Competing interests: LF and AS have read and understood BMJ policy on declaration of interests, and AS has no relevant interests to declare. LF is supported by a British Academy Postdoctoral Fellowship (award PF170028)

Provenance and peer review: Commissioned; not externally peer reviewed.

Frenck RW, Jrklein NP, Kitchin N, etalC4591001 Clinical Trial Group. Safety, immunogenicity, and efficacy of the BNT162b2 Covid-19 vaccine in adolescents. N EnglJ Med 2021

doi: 10.1056/NEJMoa2107456. pmid: 34043894

2 Moderna. Moderna announces TeenCOVE study of its covid-19 vaccine in adolescents meets primary endpoint and plans to submit data to regulators in early June. 2021. https://investors.modernatx.com/news-releases/news-release-details/moderna-announces-teencove-study-its-covid 19-vaccine.

3 Lo Re V, 3rdKlungel OH, Chan KA, Panozzo CA, Zhou W, Winterstein AG. Global covid-19 vaccine rollout and safety surveillance-how to keep pace. BMJ2021;373:n1416.

doi: 10.1136/bmj.n1416 pmid: 34144957

4 Wallace M, Oliver S. Covid-19 mRNA vaccines in adolescents and young adults: Benefit-risk discussion. Centers for Disease Control. 2021. https://www.cdc.gov/vaccines/acip/meetings/downloads/slides-2021-06/05-COVID-Wallace-508.pdf.

5 Smith C, Odd D, Harwood R, et al. Deaths in children and young people in England following SARS-CoV-2 infection during the first pandemic year: a national study using linked mandatory child death reporting data. Res Square [preprint] 2021 Jul 7. doi: 10.21203/rs.3.rs-689684/v1. https://www.researchsquare.com/article/rs-689684/v1.

6 Ward JL, Harwood R, Smith C, et al. Risk factors for intensive care admission and death amongst children and young people admitted to hospital with covid-19 and PIMS-TS in England during the first pandemic year. medRxiv [preprint] 2021.07.01.21259785; doi: 10.1101/2021.07.01.21259785.

7 Ismail SA, Saliba V, Lopez Bernal J, Ramsay ME, Ladhani SN. SARS-CoV-2 infection and transmission in educational settings: a prospective, cross-sectional analysis of infection clusters and outbreaks in England. Lancet Infect Dis 2021:21:344-53. doi: 10.1016/S1473-3099(20)30882-3. pmid: 33306981

8 Lavine JS, Bjornstad O, Antia R. Vaccinating children against SARS-CoV-2. BMJ2021;373:n1197. doi: 10.1136/bmj.n1197 pmid: 33985969 
9 Phadke VK, Bednarczyk RA, Salmon DA, Omer SB. Association between vaccine refusal and vaccine-preventable diseases in the United States: a review of measles and pertussis. JAMA 2016;315:1149-58. doi: 10.1001/jama.2016.1353. pmid: 26978210

10 Covid vaccinations tracker. New York Times 2021. https://www. nytimes.com/interactive/2021/world/covid-vaccinations-tracker.html accessed 21 June 2021.

11 Ethirajan A. As India halts vaccine exports, Nepal faces its own covid crisis. World Innovation Summit For Health. 12 May 2021. https://www.wish.org.qa/covid19/as-india-halts-vaccine-exportsnepal-faces-its-own-covid-crisis/.

12 Medicines and Healthcare Products Regulatory Agency. The MHRA concludes positive safety profile for Pfizer/BioNTech vaccine in 12- to 15-year-olds. https://www.gov.uk/government/news/the-mhra-concludes-positive-safety-profile-for-pfizerbiontech-vaccine-in-12-to-15year-olds.

13 Skelton A, Forsberg L. 3 Reasons for making covid-19 vaccination mandatory for children. Conversation13 May 2021. https://theconversation.com/3-reasons-for-making-covid-19-vaccination-mandatory-for-children-160589.

14 European Medicines Agency. First covid-19 vaccine approved for children aged 12 to 15 in EU. https://www.ema.europa.eu/en/news/first-covid-19-vaccine-approved-children-aged-12-15-eu.

15 Nirenberg E, Hoshino R. Let's recognize childhood covid as the crisis it is. Medpage Today 202 Jun 12. https://www.medpagetoday.com/opinion/second-opinions/93055.

16 Bendix, A. The Delta variant may be making covid-19 more common in kids - but severe infections are still rare. Insider 24 June 2021.

17 Global News. "We're really afraid": Kashechewan First Nation grapples with COVID-19 outbreak. https://globalnews.ca/news/7958468/kashechewan-first-nation-covid-outbreak-relief/.

18 Canadian Broadcasting Corporation. Indigenous Services minister says housing shortage aggravating COVID-19 outbreak in Kashechewan. https://www.cbc.ca/news/politics/miller-housingshortage-covid-outbreak-kashechewan-1.6077480.

19 Yamey G. Rich countries should tithe their vaccines. Nature 2021:590:529. doi: 10.1038/d41586-021-00470-9 pmid: 33627806

20 Usher AD. A beautiful idea: how COVAX has fallen short. Lancet 2021:397:2322-5. doi: 10.1016/S0140-6736(21)01367-2 pmid: 34147145

21 Burki TK. Ensuring fair distribution of COVID-19 vaccines: is an intellectual waiver the answer? Lancet Respir Med 2021;9:e64. doi: 10.1016/S2213-2600(21)00241-1. pmid: 34029536

22 Ahamed AN. Biden strikes a blow for fairness in sharing vaccine knowledge. CNN Opinion. 7 May 2021. https://www.cnn.com/2021/05/06/opinions/biden-strikes-a-blow-for-fairness-in-sharingvaccine-knowledge-ahamed/index.html.

This article is made freely available for use in accordance with BMI's website terms and conditions for the duration of the covid-19 pandemic or until otherwise determined by BMJ. You may use, download and print the article for any lawful, non-commercial purpose (including text and data mining) provided that all copyright notices and trade marks are retained. 